\title{
Centenarians in Europe
}

\author{
Laetitia Teixeira $^{\mathrm{a}, \mathrm{b}, \mathrm{c}, *}$, Lia Araújo ${ }^{\mathrm{a}, \mathrm{b}, \mathrm{d}}$, Daniela Jopp ${ }^{\mathrm{e}, \mathrm{f}}$, Oscar Ribeiro ${ }^{\mathrm{a}, \mathrm{b}, \mathrm{g}, \mathrm{h}}$ \\ ${ }^{a}$ UNIFAI, Instituto de Ciências Biomédicas Abel Salazar, Universidade do Porto, Rua Jorge Viterbo Ferreira 228, 4050-313, Porto, Portugal \\ b CINTESIS, Instituto de Ciências Biomédicas Abel Salazar, Universidade do Porto, Rua Jorge Viterbo Ferreira 228, 4050-313, Porto, Portugal \\ c EPIUnit, Instituto de Saúde Pública, Universidade do Porto, Rua das Taipas 135, 4050-600, Porto, Portugal \\ d Polytechnic Institute of Viseu, Rua Maximiano Aragão, 3504-501, Viseu, Portugal \\ e University of Lausanne, Institute of Psychology, Quartier UNIL-Mouline, Bâtiment Géopolis, CH-1015, Lausanne, Switzerland \\ ${ }^{\mathrm{f}}$ Swiss Centre of Competence in Research LIVES “Overcoming Vulnerability: Life Course Perspectives”, Quartier UNIL-Mouline, Bâtiment Géopolis, CH-1015, Lausanne, \\ Switzerland \\ ${ }^{g}$ Departamento de Educação e Psicologia, Universidade de Aveiro, Campus Universitário de Santiago, 3810-193, Aveiro, Portugal \\ ${ }^{\text {h }}$ Instituto Superior de Serviço Social do Porto, Av. Dr. Manuel Teixeira Ruela 370, 4460-362, Senhora da Hora Portugal
}

\section{A R T I C L E I N F O}

\section{Keywords:}

Centenarians

Demographic analysis

Europe

Longevity

Population ageing

\begin{abstract}
A B S T R A C T
Objectives: The group of individuals aged 80 and over is growing faster than other segments of the population, and within this group the number of centenarians has risen exponentially worldwide. This paper reports the numbers of centenarians (total, and ratio relative to total population) in 32 European countries and their key characteristics: gender distribution, level of education, and type of residence.

Study design: Population based study.

Measures: We used national census data collected in 2011 for individuals aged 100 and over living in Austria, Belgium, Bulgaria, Croatia, Cyprus, Czech Republic, Denmark, Estonia, Finland, France, Germany, Greece, Hungary, Iceland, Ireland, Italy, Latvia, Liechtenstein, Lithuania, Luxembourg, Malta, Netherlands, Norway, Poland, Portugal, Romania, Slovakia, Slovenia, Spain, Sweden, Switzerland and the UK. Data on gender, residence and education were used.

Results: The total number of centenarians was 89156, corresponding to 17.3 centenarians per 100000 inhabitants of the total population and 98.0 centenarians per 100000 individuals aged 65 and older. Centenarian ratios were highest in France, Italy and Greece, and lowest in Bulgaria, Romania, and Croatia. The percentage of men was $16.5 \%$ on average, and ranged from around $13 \%$ (Germany, Latvia, Belgium) to 37\% (Hungary). Across Europe, $62.7 \%$ of the centenarians lived in private households, with a range from $10.9 \%$ (Iceland) to $90.0 \%$ (Romania). Education levels varied across countries, with an average of $13.6 \%$ having no formal education, ranging from $0.0 \%$ (the UK, Finland, Iceland) to $61.6 \%$ (Portugal).

Conclusions: Centenarian numbers have increased substantially since last available data. The findings will inform specific health promotion policies, the strengthening of current services and the development of innovative care systems.
\end{abstract}

\section{Introduction}

A remarkable aspect of human longevity is the progressive demographic ageing of the older population itself. The group of individuals aged $80+$ is growing faster than any younger population segment, and within this group the number of centenarians has risen exponentially worldwide [1]. Despite still representing a small proportion of the total population today, the United Nations World Population Ageing report [2] projected that the number of centenarians will increase from approximately 441000 in 2013-3.4 million in 2015, and 20.1 million in 2100 .
Population ageing is particularly rapid within the European Union (EU), due to low fertility rates and decreasing old age mortality. Major improvement of survival between the ages of 80 and 100 years [1] has led to an increase of centenarians in all countries [3]. In 2006, the centenarian population was estimated to be 57306, confirming that for most recent decades the number of centenarians has doubled on average every ten years [3]. Given the speed of the demographic development, more updated information is crucial.

Presently, life expectancy in the 28 EU member countries (EU-28) is higher than in most other parts of the world. According to the last European Commission Demography Report [4], life expectancy at birth

\footnotetext{
* Corresponding author at: UNIFAI, Institute of Biomedical Sciences Abel Salazar, University of Porto, Rua Jorge Viterbo Ferreira 228, Porto, 4050-313, Portugal.

E-mail address: lcteixeira@icbas.up.pt (L. Teixeira).
} 
a)

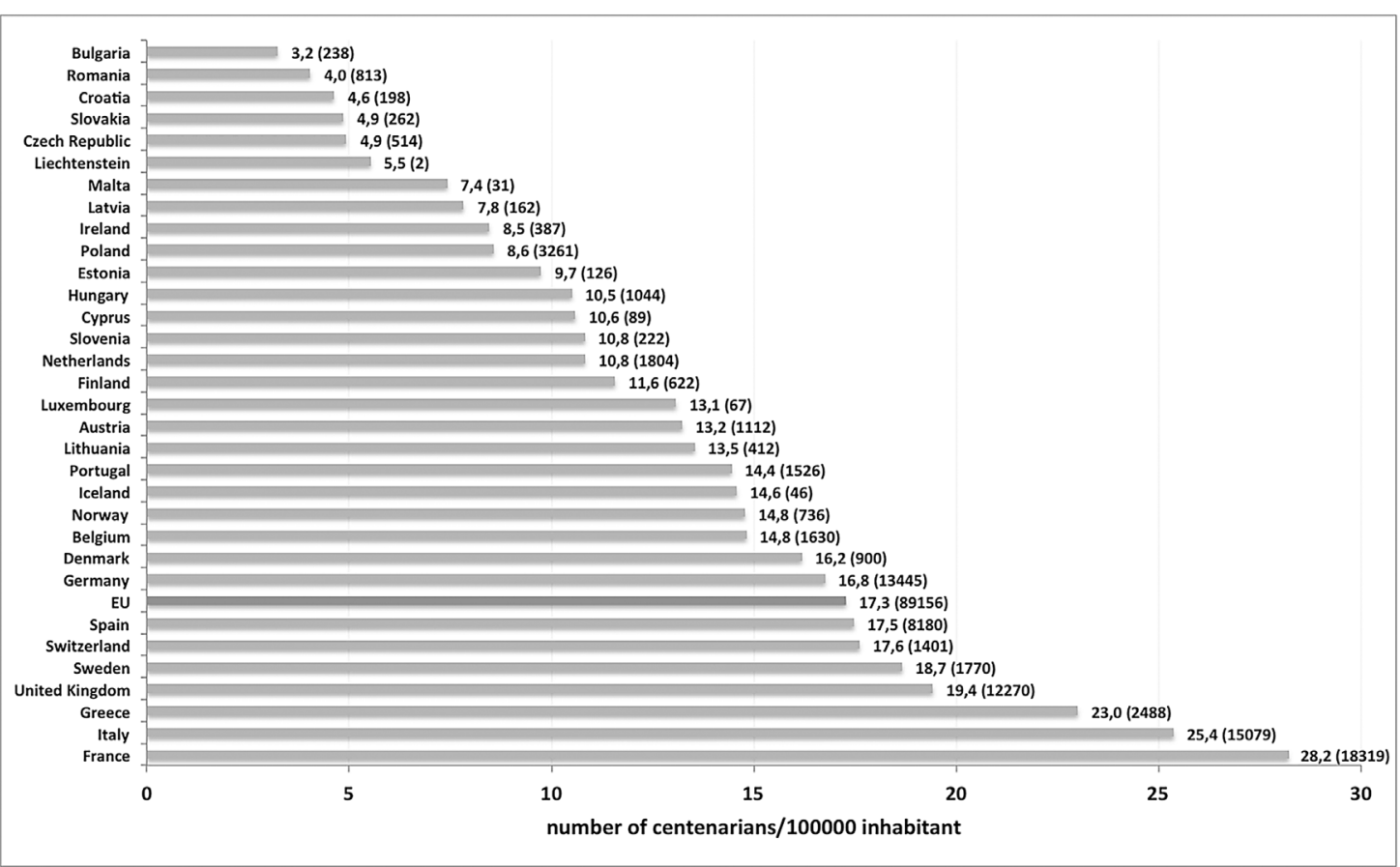

b)

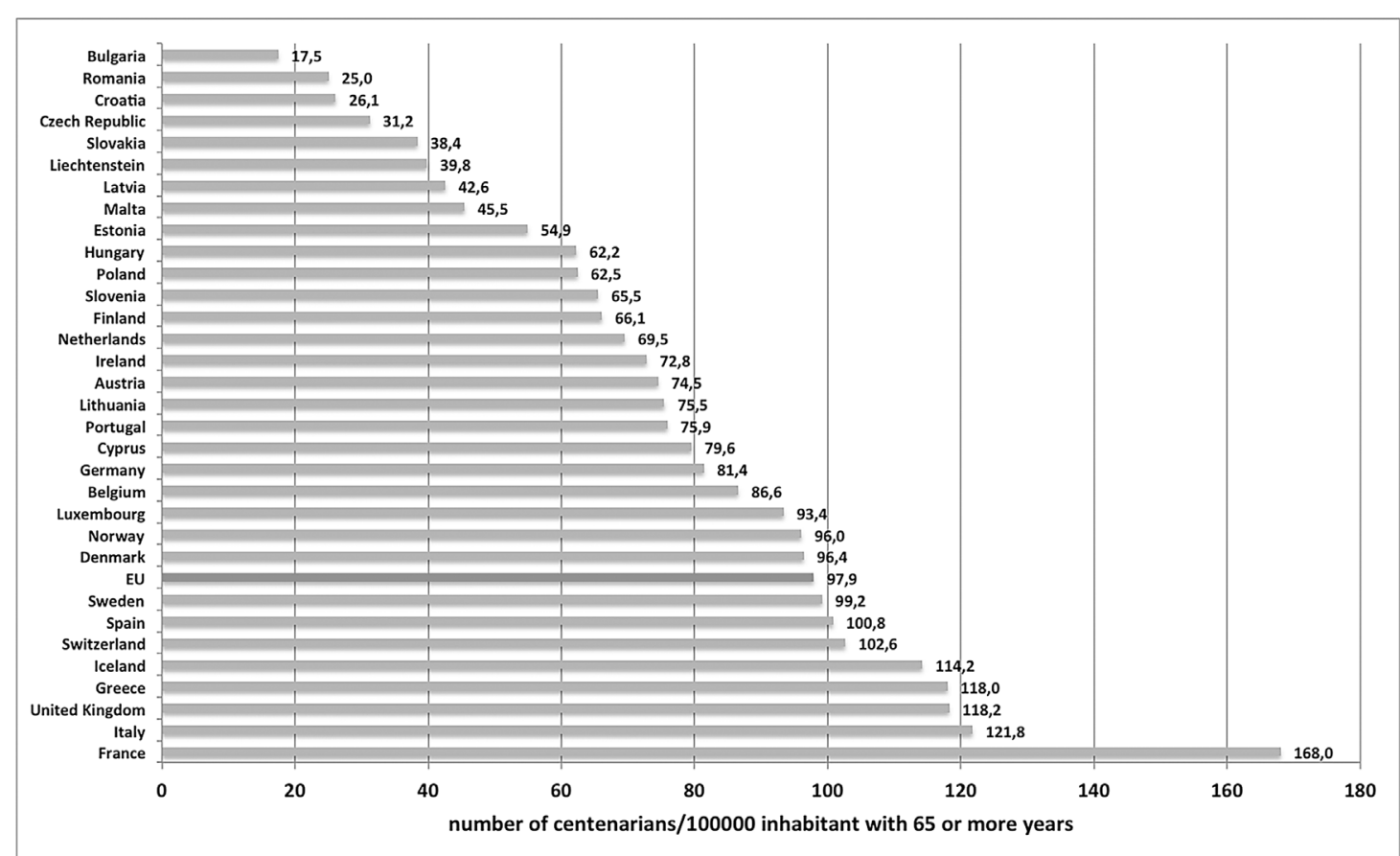

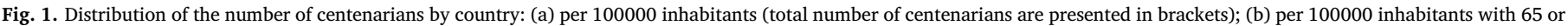
more years.

was 80.6 years in 2013 ( 83.3 for women; 77.8 for men) and life expectancy at age 65 is 19.8 years ( 21.3 for women; 17.9 years for men). The width of the gender gap varies: in 2013, reaching 65 , men could expect to live between 13.9 (Latvia) and 19.3 years (France) more years; life expectancy for women at age 65 ranged in 2011 from 17.9 (Bulgaria) to 23.6 years (France) [4]. Decline in mortality at ages 80 and over contributed more than one quarter to the increase in life expectancy at birth for women in Belgium, Greece, Spain, France, Italy, Luxemburg, Malta, the Netherlands, Austria, Portugal, Finland and Sweden; for men, the highest contribution was in Greece.

As a consequence of gender-differential life expectancy, women outnumber men significantly at age 100. A decade ago, Bezrukov and
Foig's [5] review on centenarians in Europe documented a much lower proportion of male compared to female centenarians (male/female ratios from 1:3 to $1: 8$ ), which was dramatically affected by human loss in World War II in Eastern and Central European countries. Current EU data reinforces the gender disproportion among the oldest old [4]. A notable exception is Sardinia (Italy), which shows besides a high prevalence of long-lived individuals a balanced female/male ratio for validated centenarians [6].

Addressing the major knowledge gap on Europe's current centenarian population, this paper provides an up-to-date overview of the centenarians' numeric distribution across Europe based on the last national census undertaken in EU Member States and European Free 
a)

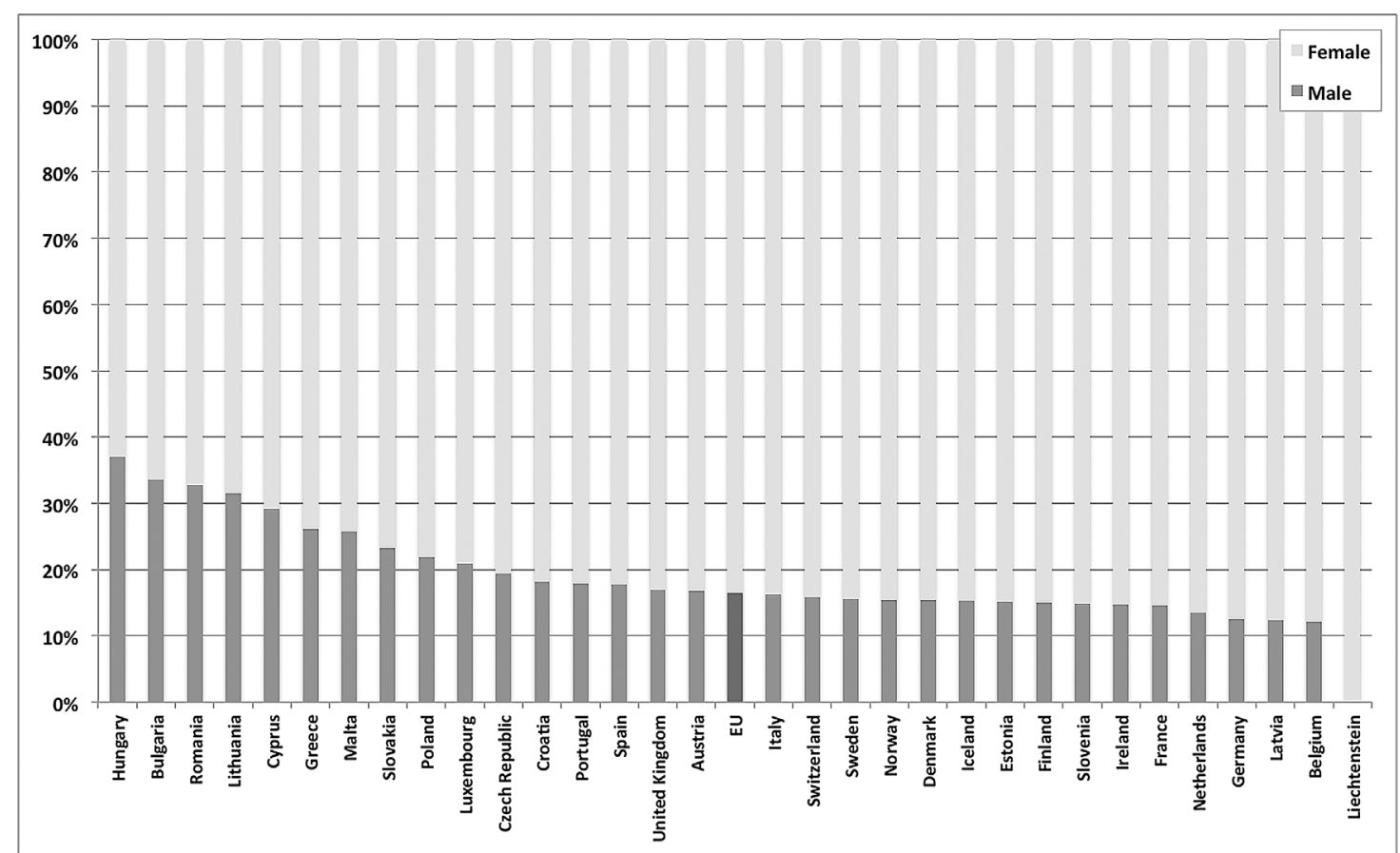

b)

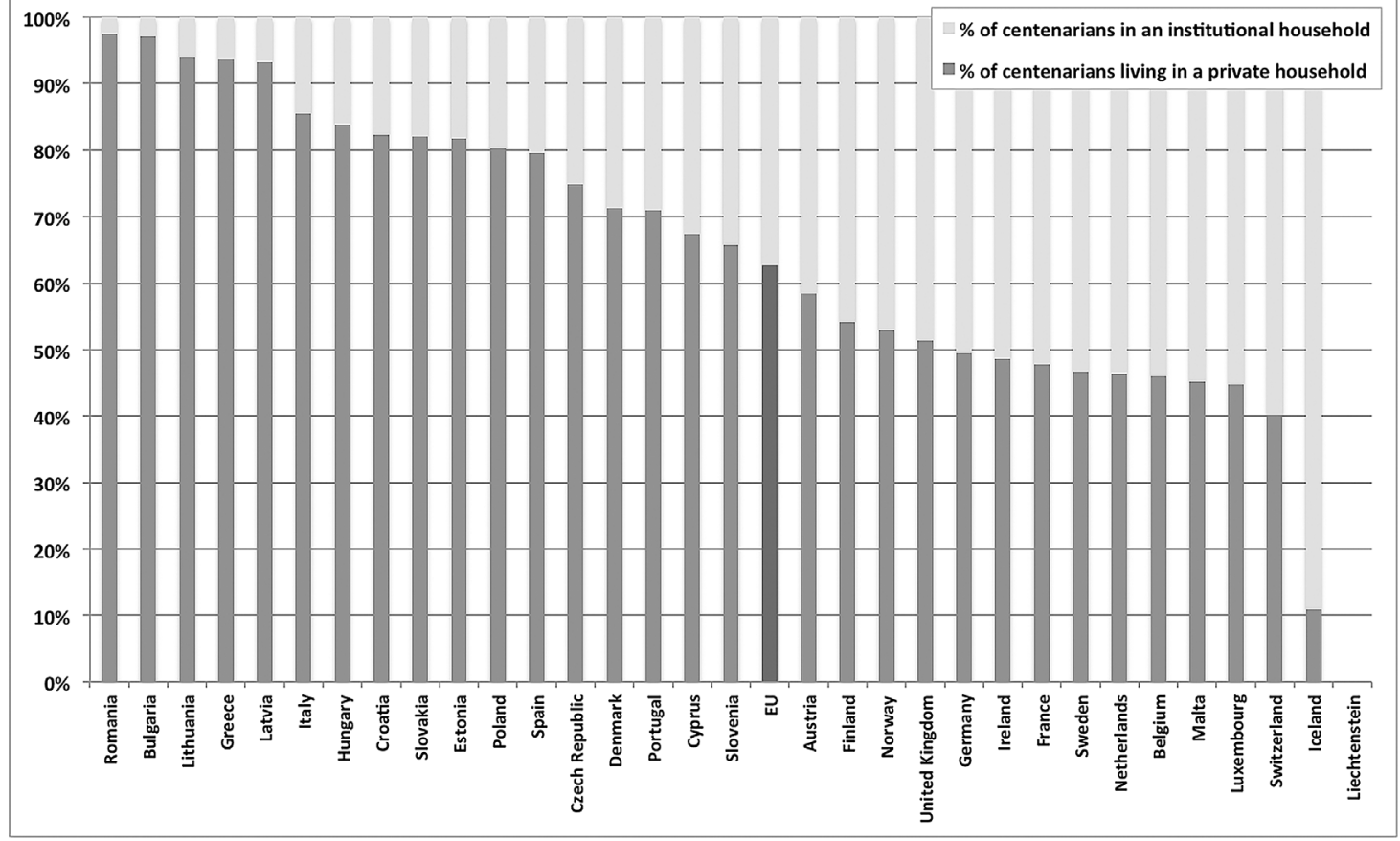

Fig. 2. Distribution of the number of centenarians by country and: (a) by gender; (b) by residence type.

Trade Association (EFTA) countries. It also offers statistics on European centenarians' gender, residence and education. This information will provide a broad picture of the European landscape of exceptional longevity and inform on current geographical inequalities that have important implications for care provision, policies and research.

\section{Methods}

\subsection{Data collection}

Centenarians' (age 100 and older) information stem from the 2011 census database and was obtained from the Eurostat website using the tool "Census Hub". The data are based on the national census undertaken in EU and EFTA countries during 2011. The tool "Census Hub" was developed by the European Statistical System (ESS) with the purpose to better disseminate the results of the Population and Housing Censuses in Europe and it is based on the concept of data sharing with collaboration to National Statistical Institutes (NSIs). In order to ensure that the census data received from the different EU Member States are comparable, the census topics followed the same technical specifications in every state [7].

\subsection{Variables}

Considering information available for people aged 100 years old and plus, the following countries were included: Austria (AT), Belgium 


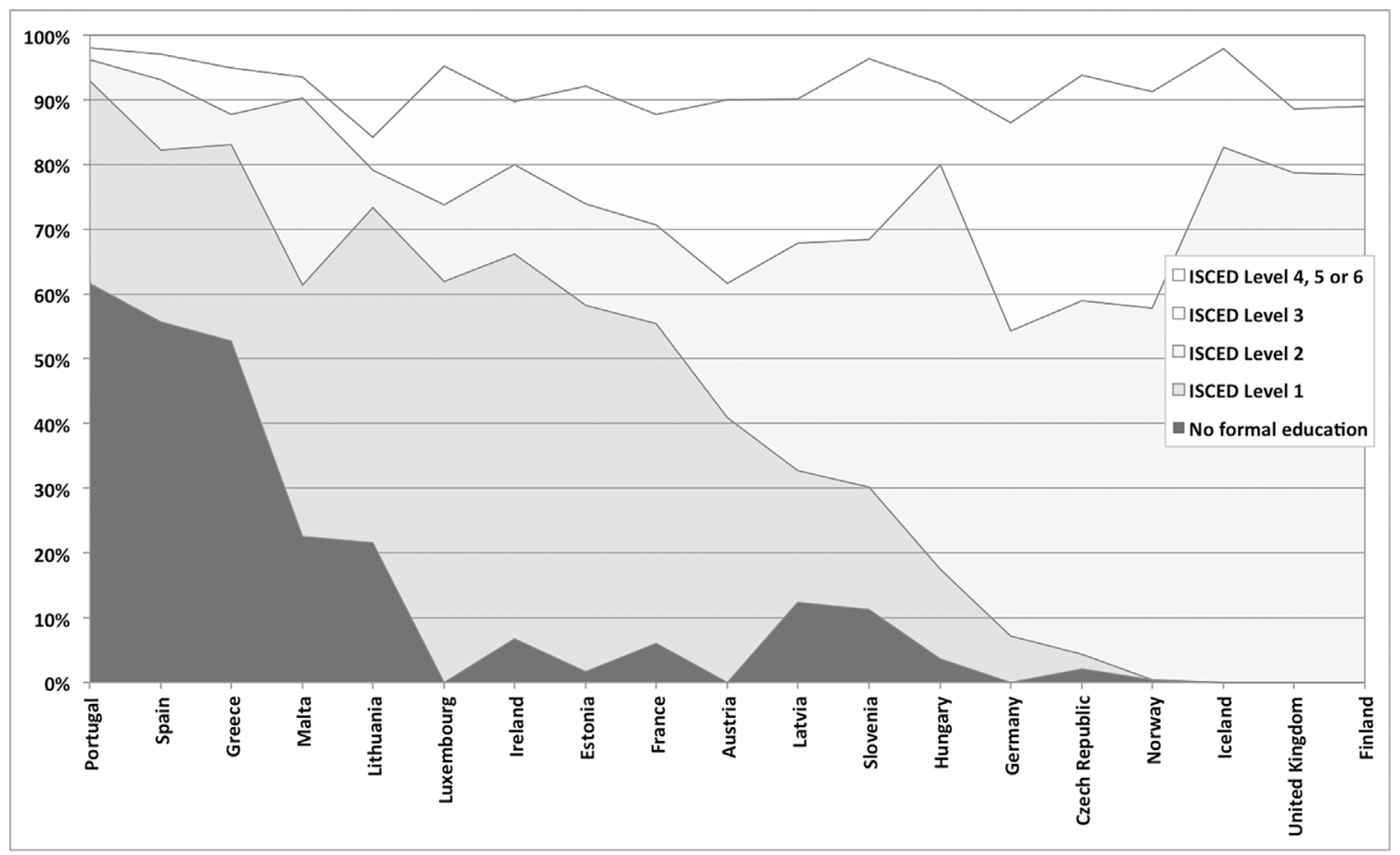

Fig. 3. Distribution of the number of centenarians by country and by education level.

(BE), Bulgaria (BG), Croatia (HR), Cyprus (CY), Czech Republic (CZ), Denmark (DK), Estonia (EE), Finland (FI), France (FR), Germany (DE), Greece (GR), Hungary (HU), Iceland (IS), Ireland (IE), Italy (IT), Latvia (LV), Liechtenstein (LI), Lithuania (LT), Luxembourg (LU), Malta (MT), Netherlands (NL), Norway (NO), Poland (PL), Portugal (PT), Romania (RO), Slovakia (SK), Slovenia (SI), Spain (ES), Sweden (SE), Switzerland $(\mathrm{CH})$ and the United Kingdom (GB). (For convenience, 'EU' is used in the below for the totality of the EU Member States and EFTA countries considered.)

Data on gender, residence and education were used: Gender included male and female categories. Residence type considered living in a private household vs. institution. Level of education followed the International Standard Classification of Education (ISCED): no formal education; ISCED 1: Primary education; ISCED 2: Lower secondary education; ISCED 3: Upper secondary education; ISCED 4+: Post-secondary non-tertiary education and higher education levels (e.g., BA, MA, Doctoral, ISCED5-8) [8]. Only valid and/or complete data were considered.

\subsection{Statistical analysis}

Descriptive analyses were performed to obtain an overview of the distribution of centenarians by countries; the number of centenarians per 100000 inhabitants and per 100000 inhabitants with 65 years and older was calculated. The distribution of centenarians by gender, type of residence and level of education were also described. Due to missing information (e.g., education), individual countries were excluded from some analyses.

\section{Results}

In 2011, the total number of centenarians in Europe was 89156, which correspond to 17.3 centenarians per 100000 inhabitants. France presented the highest ratio, with 28.2 centenarians per 100000 inhabitants (Fig. 1(a)). Italy and Greece also showed ratios higher than 20 centenarians per 100000 inhabitants, 25.4 and 23.0 respectively. Czech Republic, Slovakia, Croatia, Romania and Bulgaria had the lowest centenarian ratios, with values between 4.9 and 3.2 centenarians per
100000 inhabitants. Considering the older population (65 years and older) as reference, Europe had on average a centenarian ratio of 98.0 of 100000 inhabitants (Fig. 1(b)). Again, this ratio was highest in France with 168 , being followed at a considerable distance by Italy (121.8), the UK (118.2), Greece (118.0) and Iceland (114.0).

\subsection{Gender}

The total number of male centenarians was 14691, representing $16.5 \%$ of the European centenarian population. The proportion of men was highest in Hungary, Bulgaria, Romania and Lithuania, with percentages above $30 \%(37.0 \%, 33.6 \%, 32.7 \%$ and $31.6 \%$, respectively; Fig. 2a). Besides Lichtenstein offering only female centenarians, Germany, Latvia and Belgium had the lowest percentages of male centenarians (below 13\%).

\subsection{Residence}

The percentage of community-dwelling centenarians in Europe (excluding Liechtenstein where information was not available) was $62.7 \%$, revealing that the majority of centenarians lived in the community. Romania, Bulgaria, Lithuania, Greece and Latvia presented the highest percentages of community-dwelling centenarians, with values above $90 \%$ (Fig. 2b). Iceland had the lowest percentage (10.9\%).

\subsection{Education}

On average, $13.6 \%$ of the EU centenarians had no formal education. Reliable information about education level of centenarians was available for a group of countries only (Fig. 3). The subgroup with lowest education levels included Portugal, Spain and Greece: over half of centenarians in these countries had no formal education (Portugal: 61.6\%; Spain: $55.7 \%$, Greece: $52.7 \%$ ) and about one third to one fourth had only primary education (Portugal: $31.3 \%$; Greece: $30.4 \%$; Spain: $26.6 \%$ ). The subgroup with the highest education included Finland, United Kingdom and Iceland: all centenarians from these countries had at least lower secondary education $(78.5 \%, 78.7 \%$ and $82.6 \%$, respectively). The remaining countries showed median education, with 
centenarians distributed across all levels.

\subsection{Discussion}

This study presented the most recent numbers of centenarians in Europe, revealing that there were at least 89156 individuals being 100 years and older in 2011. In comparison to the 57306 centenarians estimated to live in Europe in 2006 [3], their number has almost doubled in 5 years, which represents an increase that is twice as fast than previously observed, as the number of centenarians used to double in 10 years [3]. This stunning recent increase as well as the notable proportion of centenarians observed in most European countries, and particularly the proportion per 100000 inhabitants with 65 or more years, stresses the remarkable rise of this age group within the older cohorts and confirms prior evidence [9] that this group has been growing more rapidly than the older population as a whole.

Most centenarians currently live in France, the country with the highest centenarian ratio, they are predominantly female (83.8\%), most live in the community $(62.7 \%)$ and vary substantially in education levels (ranging from $61.6 \%$ with no formal education in Portugal, to $82.6 \%$ with at least lower secondary education in Iceland). These findings provide a descriptive overview of the EU centenarian population, enriching the available information from a global perspective.

Although our study discloses that the likelihood of becoming a centenarian varies substantially across the European countries, France, Italy and Greece occupy a leading position with more than 20 centenarians per 100000 inhabitants. Along with Spain, all these Mediterranean countries presented a proportion of centenarians higher than the European mean (17.4 centenarians per 100000 inhabitants). Czech Republic, Slovakia, Romania and Bulgaria, from Eastern Europe, have the lowest ratios, presenting values between 3.2 and 4.9 centenarians per 100000 inhabitants. This South-Western/Eastern European division confirms previously observed trends [3] in which France and Italy were the countries with most centenarians (no available data for Greece in the previous study), and Czech Republic, Slovakia and Bulgaria were the ones with fewest centenarians (no available data for Romania).

Extreme longevity in Europe constitutes a global phenomenon, yet historical, cultural, biological, psycho-behavioural and socioeconomic factors shape variations across countries [5]. Our findings on European differences parallel earlier observations that centenarians became more prominent at different times across countries [3]: the rise of the centenarians was first documented in Sweden, then after World War II in England and Wales. In Northern countries like Ireland and Iceland the increase began later (1960s and 1970s, respectively), but did not start in countries like Portugal and Bulgaria until the 1980s and even 2000s. On the basis of these developments one could speculate that stable political (e.g., democratic) systems enhance life conditions and health care for most citizens, which positively influences longevity. Even short-term changes can have an impact: life expectancy increased over a rather short time period after German reunification for former GDR citizen, including very old individuals [10]. Furthermore, the high centenarian prevalence in France, Italy and Greece observed in our study strengthen debates about the Mediterranean-style diet and the French paradox, i.e., the lower-than-expected CHD mortality rate although classic CHD risk factors are not less prevalent than in other industrialized countries [11]. What unites the countries with lowest centenarian proportion is that they are all from the former east-bloc. Thus, these countries may still be affected by the aftermath of yearlong communist regimes, suffering from suboptimal health care, poverty and political uncertainties.

The high average proportion of centenarian women $(83.8 \%)$ throughout Europe reflects the feminization of the oldest old, paralleling individual centenarian studies [12]. Our findings document highest proportions of men in Hungary, Bulgaria, Romania and Lithuania, whereas Germany, Latvia and Belgium showed the lowest proportions. Despite the absence of a clear geographical pattern, centenarian men were highly concentrated in Eastern European countries, which may suggest a selective survival phenomenon. However, observations of $40 \%$ of male centenarians are unusual for populationbased studies. Such almost equal gender distributions for Eastern countries also stand in contrast to studies with younger populations [13]. Consequently, one may wonder whether age validation may lead to a different picture. Yet, in Sardinia, one of the blue zones with an exceptional high centenarian prevalence, the gender ratio in age-validated cases is also balanced [6]. Thus, our findings reinforce the need for more research on gender differences in exceptional longevity which takes into account not only well-established genetic, hormonal and phenotypical differences but complex constellations of socio-psychological variables including education, behaviour, social roles and inequality, as well as patterned social and medical support [14].

Another noteworthy finding concerns the observed educational differences. While Southern countries like Portugal, Spain and Greece, presented lowest education levels, Northern countries (Finland and Iceland) and UK had the highest levels. Of particular importance for these differences seem schooling regulations during centenarians' growing up: While in the UK, education from ages 5-13 became compulsory in 1893 [15], primary education was only established in Portugal in 1911, the year in which the youngest of our centenarian cohorts was born. As lower education seriously limits the ability of older persons to obtain information, access services, or take part in social, economic or political activities, it is important to consider how to improve general and health literacy. Poor education levels need also to be considered in centenarian research because of their methodological implications [16].

The proportion of community-dwelling centenarians varied notably across countries, ranging from $11 \%$ to $98 \%$. This may indicate that centenarians' level of autonomy differs by countries. However, countries provide different support to their centenarians, and factors like care services and health expenditure are associated with centenarian rates [17]. Living in the community depends also on informal caregivers. In our study, more community-dwelling centenarians were found in some Southern countries such as Greece or Italy, which show strong family commitment [18]. However, community living may also mirror the absence of formal care structures and/or economic constrains, which is likely for the Eastern countries with the highest rates of community-dwelling centenarians such as Romania and Bulgaria. The country with the lowest percentage of community-dwelling centenarians in our study was Iceland. This is particularly interesting as the government covers nursing services at home, and costs of other home services are proportional to income [19]. Investigation of such outliers may help to better understand the dynamics between person aspects (centenarian health, financial resources and caregiver capacity), societal (nursing home availability), as well as cultural factors (familism, attitude towards professional care).

The findings presented in this study provide the most up-to-date picture of the European centenarian population. This is important information as it illustrates the extent to which recent demographic developments influence the Europe ageing landscape. Nevertheless, a relevant limitation deserves mention and this relates to data quality: although based on governmental data concerning age, census procedures do not require age validation, which is a crucial aspect in centenarians studies [20]. Consequently, some individuals may be younger than indicated, which may contribute to some of the somewhat unexpected differences observed between countries (e.g., larger proportion of male centenarians in some Eastern countries). Still, the present data is likely to be more representative compared to studies with smaller participant numbers and less population-based recruitment approaches. 


\section{Conclusions}

The substantial increase in European centenarians documented in this paper highlights the urgent need to gain more detailed information about the very old to adjust long-term care and welfare systems to these new challenges. Presented findings help illustrate demands for specific policy that target prevention and health promotion, enhance current services (e.g., development of home services and increased coordination among care partners, better management of hospital admissions and discharges), as well as advancement of innovative care systems, among others [21]. Reaching an exceptional age has important implications in population needs and capacities, particularly in terms of service planning, medical costs, intergenerational interactions, and the solvency of age-based entitlement programs [1,22,23].

\section{Contributors}

LT wrote the manuscript and performed data analysis.

LA wrote the manuscript.

DJ critically revised the paper for important intellectual content.

OR critically revised the paper for important intellectual content.

\section{Conflicts of interest}

The authors declare that they have no conflicts of interest.

\section{Funding}

This research did not receive any specific grant from funding agencies in the public, commercial, or not-for-profit sectors.

\section{Ethical statement}

We confirm that any aspect of the work covered in this manuscript involved either experimental animals or human patients.

\section{Provenance and peer review}

This article has undergone peer review.

\section{References}

[1] A. Herm, K. Cheung, M. Poulain, Emergence of oldest old and centenarians: demographic analysis, Asian J. Gerontol. Geriatr. 7 (1) (2012) 19-25.

[2] U. Nations, World Populationageing 2013, Department of Economic and Social Affairs PD, 2013.

[3] J.-M. Robine, Y. Saito, The Number of Centenarians in Europe, European Papers on the New Welfare, 2009.

[4] E. Union, Short Analytical Web Note 3/2015. Demography Report, Publications Office of the European Union, Luxembourg, 2015.

[5] V. Bezrukov, N. Foigt, Longevidad centenaria en europa, Rev. Esp. Geriatr. Gerontol. 40 (5) (2005) 300-309.

[6] M. Poulain, G.M. Pes, C. Grasland, C. Carru, L. Ferrucci, G. Baggio, C. Franceschi, L. Deiana, Identification of a geographic area characterized by extreme longevity in the Sardinia island: the AKEA study, Exp. Gerontol. 39 (9) (2004) 1423-1429.

[7] E. Commission, EU Legislation on the 2011 Population and Housing CensusesExplanatory Notes, Eurostat Methodologies and Working Papers, EU Commission, 2011.

[8] U.I.f. Statistics, International Standard Classification of Education: ISCED, UIS, Montreal, Quebec2012, 2011.

[9] UNFPA, H. International, Ageing in the 21st Century: A Celebration and A Challenge, UNFPA and HelpAge, New York, 2012.

[10] R. Scholz, H. Maier, German Unification and the Plasticity of Mortality at Older Ages, Max-Planck-Institute for Demographic Research Working Paper 31, (2003).

[11] M. De Lorgeril, P. Salen, F. Paillard, F. Laporte, F. Boucher, J. De Leiris, Mediterranean diet and the French paradox, Cardiovasc. Res. 54 (3) (2002) 503-515.

[12] X. Tigani, A.K. Artemiadis, E.C. Alexopoulos, G.P. Chrousos, C. Darviri, Gender differences in Greek centenarians. A cross-sectional nation-wide study, examining multiple socio-demographic and personality factors and health locus of control, BMC Geriatr. 11 (1) (2011) 87.

[13] CIA, CIA World Factbook, 2017, (2017) https://http://www.cia.gov/library/ publications/the-world-factbook/fields/2018.html.

[14] F. Balard, I. Beluche, I. Romieu, D.C. Willcox, J.-M. Robine, Are men aging as oaks and women as reeds? A behavioral hypothesis to explain the gender paradox of French centenarians, J. Aging Res. 2011 (2011)

[15] C. Garrouste, 100 Years of Educational Reforms in Europe: A Contextual Database, (2010).

[16] P. Sachdev, C. Levitan, J. Crawford, Methodological issues in centenarian research: pitfalls and challenges, Asian J. Gerontol. Geriatr. 7 (2012) 44-48.

[17] J.I. Kim, Social factors associated with centenarian rate (CR) in 32 OECD countries, BMC Int. Health Hum. Rights 13 (1) (2013) 16.

[18] P.P. Viazzo, An ageing population, institutional context and family values in southern europe, in: J. Troisi, H.J. von Kondratowits (Eds.), Ageing in the Mediterranean, Policy Press, 2013, pp. 57-74.

[19] A. Europe, Iceland 2005: Home Care, Background Information About Dementia and Home Care Services, (2017) http://www.alzheimer-europe.org/Policy-inPractice2/Country-comparisons/2005-Home-care/Iceland.

[20] L.W. Poon, M. Jazwinski, R.C. Green, J.L. Woodard, P. Martin, W.L. Rodgers, M.A. Johnson, D. Hausman, J. Arnold, A. Davey, Methodological considerations in studying centenarians: lessons learned from the Georgia centenarian studies, Annu. Rev. Gerontol. Geriatr. 27 (1) (2007) 231.

[21] B. Rechel, E. Grundy, J.-M. Robine, J. Cylus, J.P. Mackenbach, C. Knai, M. McKee, Ageing in the European union, Lancet 81 (9874) (2013) 1312-1322.

[22] B.A. Carnes, S.J. Olshansky, L. Hayflick, Can human biology allow most of us to become centenarians? J. Gerontol. Ser. A: Biol. Sci. Med. Sci. 68 (2) (2013) 136-142.

[23] D.S. Jopp, K. Boerner, O. Ribeiro, C. Rott, Life at age 100: An international research agenda for centenarian studies, J. Aging Soc. Policy 28 (3) (2016) 133-147. 